organs for propulsion of the whale, as the propellers are in a ship, and the importance of the tail (hind part of the body) corresponds to that of the ship's engine which moves the propeller.

If we compare the size of the propeller of a steamship with the size of the ship, the propeller seems small, and still it may, in spite of its slight effective power, propel the ship; the tail fin of a dolphin or a whale is not smaller in comparison with the size of these animals than the propeller of the steamship, but larger, if anything. Thus, bearing in mind the obviously far greater effective power of the fins of the whales, it is not to be wondered at that these animals may follow the biggest steamships with ease, and even follow our quick destroyers ; in fact, a harpooned whale may carry away a steamship with great velocity through the water, in spite of the steamer backing full speed with its propeller.

I have presumed that the anatomy of the tail and the tail fin is mainly the same in the porpoise as in the other whales; this, however, as well as so many other things concerning this matter, I must leave to others, who may get an opportunity to examine it more closely.

\title{
Physics in Radiology.
}

SEVERAL notable papers were read before the Physics Section of the International Congress of Radiology, which was held at the Central Hall, Westminster, on June 30-July 4. The work of the Congress began with a joint discussion, in which the Physics and Radiology Sections met for a full day's consideration of the difficult problem of X-ray measurement. This discussion was opened at Io A.M. on July I before a large attendance, by Sir William Bragg and Dr. Beclére, the president (Dr. T. Holland) occupying the chair. The importance of such a discussion, in which representative men from practically all over the world took part, is obvious, and it is satisfactory to be able to report that the practical outcome has been a definite proposal as to the mode of initiating the formation of an International Committee to deal with the matter.

Sir William Bragg dealt generally with the importance of physical measurements and referred to the difficulties already met with in determining the brightness of light. He pointed out that the X-ray problem has special added difficulties of its own. First comes the question of a unit, and then the production of standards to be expressed in terms of the agreed unit, and finally it remains to ascertain what biological effects are associated with certain rays, or groups of rays, so measured. He was hopeful that a successful issue will ultimately result from the efforts now being made throughout the world towards setting up a suitable system of X-ray measurement, but he warned his hearers that the question of an $\mathrm{X}$-ray unit is beset with more difficulties than have ever been met with in the case of any other unit which science has been called upon to devise. Finally, he directed attention to the principles which must underlie such a system, and set the problem clearly before the meeting.

Dr. Beclére, of Paris, spoke more in detail with reference to the conditions which the medical radiologist has to face, referring to the pioneer work of Villard, and discussing the actual methods of measurement suggested by Solomon, Krönig and Friederich, Seit and Wintz, and others. He made an eloquent appeal for international unity in regard to the question of X-ray measurement.

On the conclusion of the formal opening of the discussion, the chairman of the Physics Section (Major C. E. S. Phillips) presided for the rest of the day. In the course of his remarks, Dr. Beclére strongly urged the setting up of an International Committee to deal with X-ray measurements, and Dr. Finzi, who spoke later, also directed attention to the matter and seconded Dr. Beclére's proposal, which on being put to the meeting was carried with enthusiasm.

Dr. Beclére was followed by Dr. Solomon (France), Dr. Behnken (Germany), Prof. Grebe (Germany), Dr. Altschul (Czechoslovakia), Dr. Shaxby (Cardiff), who read a communication from Dr. A. Dauvillier
(France), Dr. Finzi (London), Dr. Moore (London), Prof. Wintz (Germany), Dr. Reyjeski (on behalf of Prof. Dessauer), Dr. Glasser (U.S.A.), Prof. Friederich (Germany), Dr. Mallet (France), Dr. Holdfelder (Germany), Prof. Holthusen, Dr. Coliez, Prof. Crowther (Reading), Prof. Russ (London), and Dr. Ernst (U.S.A.). The chairman directed attention, at the conclusion of the discussion, to the principal points raised, and emphasised the desirability of taking steps towards the establishment of an International Committee to pursue the subject.

On Wednesday evening the Silvanus Thompson Memorial Lecture (inaugurated by the Röntgen Society) was delivered (in English) by the Duc de Broglie, and attracted an enthusiastic audience. The nature of the secondary radiations set up by $\mathrm{X}$ - and gamma rays, and attempts to understand the process by which they are initiated, are matters of great importance and interest to radiologists generally, and especially to those searching for clues as to a biophysical explanation of the effects of radiations upon tissues. The Duc de Broglie eloquently summarised our present knowledge of this subject, and gave a valuable account of some recent researches by French physicists who have been extending the work begun by Rutherford, C. T. R. Wilson, Ellis, and others, relating to the problem. At the conclusion of the lecture the Silvanus Thompson Memorial Medal was handed to the Duc de Broglie by the president.

On Thursday morning an interesting paper on the radiography of coal was read by $\mathrm{Mr}$. Norman Kemp, and Dr. Bouers then described a new metal X-ray tube (Metalix) for use in radiography and X-ray therapy. This was followed by an important paper by Prof. Friederich (Freiburg) in which some new results were described. The last paper of the morning was read by Dr. Koopman, of Amsterdam, who showed a novel type of Potter-Bucky diaphragm. The variety and originality of these papers were striking, and interesting discussions followed each one of them.

In the afternoon the Section did not meet, on account of the visit to the National Physical Laboratory, which had been arranged for that day in response to the kind invitation of the Director.

The Section again met on Friday morning at Io A.M. for a discussion of methods of protection, opened by Dr. G. W. C. Kaye, of the National Physical Laboratory. An animated debate followed, to which M. Pilon (Paris) sent a written contribution (read by Mr. Gough), and the following took part: Dr. Ferreaux (Paris), Mr. Pullin (London), Dr. Pirie (Montreal), Dr. Shaxby (Cardiff), and Dr. Moore (London). Dr. Kaye, in his reply, directed attention to the need of standardising the scheme of protection, and proposed the following resolution, which was seconded by Mr. Pullin and unanimously agreed to:

"That the Physics Section of the first International

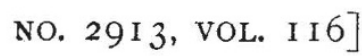


Congress of Radiology wishes to place on record the desirability of adopting a standard scheme of X-ray and radium protection throughout the world."

The morning session was brought to a close with a valuable paper by Prof. F. L. Hopwood, who dealt in detail with the organisation of a hospital radium service. Considerable discussion ensued, in which Dr. Ferreaux, of the Radium Institute, Paris, and Dr. Failla, of the Memorial Hospital, New York, took part.

The afternoon session was opened with a paper (read in title only) by Dr. George Clark (U.S.A.), which was followed by an interesting contribution by Dr. Lewis Simons (London), entitled "The Basis of the Selective Chemical Action of X-rays and Light," and the work of the Section was brought to a close by a discussion dealing with modes of producing currents at constant high potential. This discussion was opened by the chairman (Maj. C. E. S. Phillips), who gave a general survey of the subject. Many speakers stated their views, and Prof. Dessauer described his new methods now in use in Germany. Dr. Moore, Mr. Gunstone, and others contributed to the discussion in which all were agreed as to the desirability of adopting constant high-tension apparatus for accurate physical or therapeutic work.

It is clear from the work of the Congress that physics is playing an important part in the progress of medical radiology, and that the scope of its use- fulness is ever widening, The study of X-ray spectroscopy, for example (to mention only one aspect of it), has already lead to the design of wave-length measuring instruments for use in the ordinary routine work of a medical X-ray department, as well as furnishing a knowledge of organic structures unobtainable by other means. A well-organised exhibition of apparatus held in conjunction with the Congress also testified to the many practical applications that have arisen from work in radiation physics, which has been carried out in many parts of the world during recent years, as well as to the ingenuity of those who provide appliances for medical radiologists.

The truly international character of the Congress was very striking. There were representatives from India and Iceland, from Sweden, Russia, Czechoslovakia, France, Belgium, Germany, Italy, U.S.A., Canada, and so forth; and it was a remarkable fact that this great medical meeting had been made possible by the researches of a physicist whose rare distinction it was to have given to the world a discovery of such far-reaching possibilities for the good of mankind. It was generally acknowledged that the Congress had proved a success; it had, in fact, brought together representative men from many parts of the world, whose enthusiasm was tempered only by a desire to advance cautiously in a field of medical work which is admittedly still imperfectly understood.
C. E. S. Philirips.

\section{Industrial Water Supply.}

\section{T'H}

$\mathrm{HE}$ subject of industrial water supply and stream pollution was discussed at the joint meeting of the Institution of Chemical Engineers and the American Institute of Chemical Engineers, which was held on July I7, in Leeds. Messrs. F. P. Veitch and L. C. Benedict, of the Bureau of Chemistry (U.S.A.), contributed a valuable paper on the composition and disposal of wool-scouring waste liquors, in which they described current methods of recovering wool-grease and fertilising material from them, as well as recent work done by the Bureau which indicates the superior advantages of extracting with naphtha and subsequent scouring with soap and water. They estimate that the wool-scouring liquors annually produced in the United States contain, in millions of pounds weight, grease $60-70$, potash salts $40-48$, nitrogenous matter $\mathrm{I}_{5}$, and dirt $60-90$, the total value of which is about 5 million dollars. The authors are convinced that wholesale economic recovery of the valuable ingredients is possible.

Mr. W. L. Stevenson, chief engineer to the Department of Health, Commonwealth of Pennsylvania, criticised most legislative efforts to control pollution of streams as being too peremptory and too punitive, and he advocated the policy of scientific and friendly co-operation between municipality and manufacturer; such a policy is successfully pursued by the Sanitary Water Board of Pennsylvania, which, inter alia, has re-classified the waters of that State on the principles of conservation and controlled utilisation. The nature of the restrictive and penalising legislation passed by most States was well shown by Mr. E. B. Besselievre, of New York, whose paper included a summary of the rules upon which the decisions of courts of justice have been based. Mr. H. C. Parker, of Pennsylvania, described recent developments and improvements in the apparatus used for determining hydrogen-ion concentration in industrial effluents and sewage liquors.

Of the papers presented by British workers, that by Dr. T. Lewis Bailey, of the Ministry of Health, on effluents from ammonia plants of coke-oven and gas-works, was of outstanding importance. Such effluents, it is well known, are the source of much trouble at sewage-disposal works, and Dr. Bailey has for years past been investigating methods of prevention and cure. $\mathrm{He}$ described the probable origins of, and the possible ways of eliminating, the harmful ingredients (chiefly ammonium thiocyanate, ammonium thiosulphate, phenol, organic bases and higher tar-acids), but holding that prevention is better than cure, he indicated how relatively clean ammoniacal liquors can be produced by minimising the time of contact between tar and liquor, and by rapidly cooling the crude gas in water-cooled systems, together with rigid exclusion of " adventitious" air. Bad effluents from ammonia plants can be successfully purified in percolating filters, given proper dilution and adequate regulation, although this method is seldom practicable at gas-works owing to lack of the necessary ground space.

Mr. R. D. Littlefield, also of the Ministry of Health, retold the interesting tale of how the Royal Commission on Sewage Disposal solved the problem of purifying the effluents from Scottish distilleries. Here again the percolating filter did what was required, after suitable inoculation.

Water-softening by the base-exchange method was the subject of two contributions. Dr. E. B. Higgins and Mr. J. P. O'Callaghan summarised the advantages which this method has over the older lime-soda process, and described in outline the preparation of "Permutit," both the artificial material (made from sodium silicate and sodium aluminate) and the natural material, which is prepared from greensand or glauconite. In their opinion, natural zeolite is the better owing to its rapidity of action and of regeneration with sodium chloride solution, as well as on account of its superior mechanical and chemical stability. On the other hand, Dr. T. P. Hilditch and Mr. H. J. Wheaton claimed that the water-softener "Doucil" is practically free from the defects which the previous authors held to be inherent in all such artificial base-exchange materials. 